\title{
Vigilância em Saúde do Trabalhador: a tentação de engendrar respostas às perguntas caladas
}

\author{
Worker's Health Surveillance - The temptation of making up \\ answers for unaskable questions
}

\author{
${ }^{1}$ Departamento de Nutrição Social, \\ Faculdade de Nutrição, Universidade \\ do Rio de Janeiro (UERJ). Rio de Janeiro, \\ RJ, Brasil. \\ Contato: \\ Fátima Sueli Neto Ribeiro \\ E-mail: \\ fatsue@uerj.br
}

O trabalho não foi subvencionado.

A autora declara não haver conflitos de interesse.

\section{Resumo}

Este texto pretende refletir a implementação da Vigilância em Saúde do Trabalhador (Visat) no Sistema Único de Saúde (SUS). O recorte teórico adotado se situa em uma perspectiva crítica da área de Saúde do Trabalhador com práticas tradicionais que ainda não incorporaram o contexto do capitalismo mundializado, a globalização do consumo e das relações sociais, a flexibilização das relações sociais e sua repercussão na dinâmica social do sujeito coletivo. A partir da práxis no SUS, analisa os possíveis motivos pelos quais as ações de Vigilância em Saúde do Trabalhador não são efetivadas e se o modelo atual atende às demandas modernas do mundo do trabalho sob os princípios de equidade e integralidade do SUS. Destaca a necessidade de superar o modelo de vigilância centrado em agravos e de modernização de suas práticas para uma atuação sobre os determinantes sociais no contexto do capitalismo atual. Refletindo acerca da produção teórica atual e das práticas no modelo do SUS, propõe uma atuação baseada em pactuação de cenários, adoção de novos indicadores e avaliação sistemática e contínua das ações em uma Vigilância Antecipatória de Cenários, bem como conjectura algumas ações de curto, médio e longo prazos para a área.

Palavras-chave: saúde do trabalhador; vigilância antecipatória de cenários; vigilância em saúde do trabalhador; Sistema Único de Saúde.

\begin{abstract}
This paper purpose is to ponder about the implementation of Worker's Health Surveillance in the Brazilian Unified Health System (SUS).The theoretical framework adopted is a critical perspective of the Worker's Health area, including its traditional practices that have not incorporated the globalized capitalism context, the globalization of consumption and of social relations, the flexibility of these social relations and its impact on the collective subject social dynamics. Starting from the praxis in the Unified Health System (SUS), the paper analyzes why Worker's Health Surveillance actions have not been taken by SUS and if the program present model meets the modern labor world demands under SUS equity and integrality principles. The paper emphasizes it is necessary not only to improve the surveillance model, which is focused on diseases, but also to update its practices so that it can act on the social determinants of contemporary capitalism. Based on theoretical reflection on SUS model and its practices, the paper proposes action based on agreed scenarios, implementing of new indicators, systematic and continuous assessment of actions towards an Anticipatory Surveillance of Scenarios and suggests some short, medium and long term practices for the area.
\end{abstract}

Keywords: occupational health; anticipatory surveillance of scenarios; worker's health surveillance; Brazilian Unified Health System. 


\section{Introdução}

Conceitualmente, a vigilância é um espaço estratégico do Estado que recolhe evidências e desencadeia ou recomenda ações. Compreende necessariamente uma pré-concepção ou um modelo (implícito ou explícito) de ações de saúde que, por sua vez, está carregada de teoria (ou de uma visão do mundo) que se consubstancia em um método para apreensão da realidade, que então é decodificada em evidências capazes de serem implementadas no modelo. No Estado autoritário, a vigilância é exercida para restringir ou eliminar direitos dos cidadãos. No Estado democrático, a vigilância é exercida para garantir os direitos dos cidadãos. Nesse contexto, a vigilância em saúde é a expressão máxima de intervenção do Estado democrático e de direito no sentido de garantir a saúde dos cidadãos (VASCONCELLOS, 2007).

Saúde do Trabalhador, conforme definido na Lei no 8.080 (BRASIL, 1990), já configurava a obrigatoriedade das estruturas de vigilâncias do SUS incorporarem este campo no conjunto de atividades cotidianas. Todavia, destaca que sua abordagem deve se dar no marco da integralidade (promoção, proteção, recuperação e reabilitação):

como um conjunto de atividades que se destina, através das ações de vigilância epidemiológica e vigilância sanitária, à promoção e proteção da saúde dos trabalhadores, assim como visa à recuperação e reabilitação da saúde dos trabalhadores submetidos aos riscos e agravos advindos das condições de trabalho. (BRASIL, 1990, capítulo I, $\operatorname{art}^{\circ} 6^{\circ}$, parágrafo $3^{\circ}$ )

Não cabe reafirmar que os agravos relacionados ao trabalho devem estar previstos nas ações da vigilância epidemiológica, mesmo porque será reafirmar a Portaria GM/MS no 104, de 25/01/2011 (BRASIL, 2011), que refere as doenças e os agravos relacionados ao trabalho em uma lista nacional de doenças de notificação compulsória. De igual mote seria discutir a ação de fiscalização dos ambientes de trabalho, especialmente do setor regulado pela vigilância sanitária. Isso também será uma redundância. $\mathrm{O}$ planejamento e a realização das ações de forma interdisciplinar, pluri-institucional e com a participação dos trabalhadores também já está detalhada nas Portarias MS no 3.908 (BRASIL, 1998b) e no 3.120 de 1998 (BRASIL, 1998a) e descrito em Vasconcellos e Ribeiro (1997).

Ainda que definida pela legislação, amparada pelos repasses de recursos e ampliada em estruturas que se multiplicaram nos últimos 10 anos, a Vigilância em Saúde do Trabalhador (Visat) fundada nos princípios e nos marcos legais da área não tem sido uma realidade no Brasil.

Duas questões suscitam a reflexão sobre as práticas de Visat no SUS: Por que estas ações não são realizadas? Se fossem realmente efetivadas, seriam suficientes frente às exigências do novo mundo do trabalho e das responsabilidades do SUS com a equidade e a integralidade?

Entorno desses dois temas, questões teóricas e opções políticas cruciais para a prática sanitária precisam ser debatidas. Os indicadores que expressam e orientam as ações da vigilância adotadas pela Saúde do Trabalhador no Brasil, constituindo as suas evidências sanitárias, priorizam indicadores de efeitos (doenças e acidentes). Seguidas de recomendação de ações que visam ao "controle do risco", indicam, a priori, a baixa possibilidade de reversão de situações tardias porquanto atuam na lógica da relação causa-efeito e privilegiam apenas a dimensão médica e tecnológica do problema, reduzindo as possibilidades de explicação e de intervenção. Vigilância, nesta perspectiva, representa uma atividade de reparação em um cenário estático de produção de riscos e, intencionalmente, não interfere nas causas, não reduz a dimensão dos agravos e não evidencia a apropriação da saúde e da vida pelo processo de produção.

Embora o risco possa ser considerado como inerente ou um paradoxo da vida humana (CASTIEL; GUILAM; FERREIRA, 2010), é fundamental localizar que esta vida está configurada socialmente por elementos políticos e culturais que sustentam e são sustentados pelo processo de produção em sua dimensão, que envolve o processo de trabalho, a distribuição, o consumo e a troca. Logo, o risco no processo de trabalho nunca é inerente, mas fruto de uma intencionalidade presente, ou negligenciado na organização do processo de trabalho e do modelo econômico.

Sob essa perspectiva, já não basta buscar a prevenção primária através dos riscos identificados na "História Natural" dos agravos relacionados com o trabalho. Para que a Vigilância possua real efetividade, cabe buscar os determinantes e antecipar-se aos problemas que as mudanças no direcionamento da economia implementam em um grupo social e no ambiente. Esta relação dinâmica, mais antecipatória do que regressiva, demanda conhecimento inter e transdisciplinar, demanda assumir o grande desconhecimento que ainda possuímos frente a situações complexas e, necessariamente, uma interlocução próxima baseada nos valores da população.

Outra forma de construir o cenário de intervenção da vigilância deve basear-se em um novo conjunto de indicadores capazes de evidenciar os efeitos sobre o corpo e o ambiente dos novos modelos de organização pós-fordistas. Nesta dimensão, a Visat se depara com a dificuldade do SUS em adotar uma concepção sistêmica, conforme discutido por Vasconcellos (2007), e prover o Estado de meca- 
nismos capazes de gerar informações, intervenções sobre os processos produtivos e outras capacidades transetoriais com vistas a interferir no modelo de desenvolvimento.

Entretanto, é justamente nessa contradição que o campo da Saúde do Trabalhador precisa subsidiar e impulsionar o SUS. Em conjunto com o campo do Ambiente, cada vez mais é propício o debate acerca das consequências para a vida no planeta do atual modelo de desenvolvimento. Emerge a necessidade da Saúde do Trabalhador instrumentalizar o aparelho estatal através de sua estrutura e mecanismos de intervenção/coerção, de modelos e estratégias de atuação voltada para novos modelos em rede e motivada pela relação mais próxima com as necessidades socioambientais.

As linhas básicas de operacionalização sob a égide da promoção da saúde e das mudanças tecnológicas já estão dadas a partir de seu arcabouço legal, embora ainda exista um universo a ser percorrido. Modelos e instrumentos de ação para superar a estratégia medicalizante da sociedade em uma atuação conjunta e corresponsável entre todos os atores sociais ainda carecem de construção, mas se configuram em uma necessidade dos tempos de comunicação imediata propiciada pela internet.

O cerne deste ensaio é a reflexão crítica da Visat ousando propor novos acordos sanitários que não fragmentem a vida em indicadores tardios de morbimortalidade, mas que atue no modelo de pactuação de cenários promotores de vida e felicidade como resposta às profundas mudanças pelas quais vem passando o mundo do trabalho nas últimas décadas. Avança na proposição de uma nova vigilância que tem como foco os determinantes sociais da saúde e o comprometimento antecipatório com cenários e riscos, assim como ações e indicadores de distintas dimensões em curto, médio e longo prazo.

\section{Por que o sistema de saúde não implemen- ta vigilância em saúde do trabalhador?}

A Visat se distingue das vigilâncias e de outras disciplinas do campo da relação trabalho-saúde pela delimitação de seu objeto específico na "investigação e intervenção na relação entre o processo de trabalho e a saúde" (MACHADO, 1996, p. 46). Entende-se como trabalho os processos produtivos organizados ou informais, urbanos ou rurais (BRASIL, 2012) e a saúde como síntese de bem estar, qualidade de vida individual e coletiva, formas culturais de preservação da existência e espécie, e sobre todos os esforços e disputas coletivas por grupo sociais diferenciados para estabelecer parâmetros acerca do significa saudável (MINAYO, 2001).
Machado (1996) alertou para o perigo de equiparar a Visat às concepções restritas de vigilância médica (de agravos) e vigilância epidemiológica. Mais do que uma questão semântica, esta redução gera consequências na competência institucional para a intervenção nos ambientes de trabalho.

Ainda que a discussão já tenha completado mais de uma década, o foco da Visat ainda ocorre na intervenção sobre os "fatores de risco" que, desta forma, pouco evoluiu para a identificação e a alteração dos fatores determinantes. Este limite, associado às restrições técnicas, situa as dificuldades de atualizar as rotinas institucionais do Estado cuja estrutura prejudica a incorporação de novas práticas capazes de inovar na abordagem mais sistêmica dos problemas de saúde.

Os obstáculos para superar as concepções restritivas das clássicas vigilâncias sanitária e epidemiológica e da vigilância médica dos agravos à saúde relacionados ao trabalho implicam na revisão de competências institucionais, na incorporação de outros atores sociais e no avanço em direção a práticas de caráter multiprofissional, interdisciplinar e intersetorial (LACAZ; MACHADO; PORTO, 2002).

Na pesquisa de Lacaz, Machado e Porto (2002), identificou-se que o maior entrave a ser superado na área da saúde do trabalhador era a intrasetorialidade, justamente o ponto focal para as ações de vigilância. Outras dificuldades referiam-se a: treinamento e capacitação das equipes, recursos materiais e investimento, integração intra SUS, legislação e legitimidade social das ações de vigilância. Embora sejam dificuldades bastante concretas, elas evidenciam partes do problema, em especial aqueles que interferem diretamente na prática profissional e podem ser vislumbrados como entrave imediato. Em um plano mais avançado, percebe-se que não há orientação ou decisão política para sua realização. As práticas locais que ocorreram no processo histórico brasileiro foram resultado do empenho quase pessoal de grupos localizados.

Costa (2011) refere que, no levantamento direto junto aos 114 Centros de Referência em Saúde do Trabalhador (Cerests) implantados no ano de 2010 e tendo obtido resposta de $32 \%$ destes, a maioria (70\%) não desenvolvia ações de vigilância e, dos que referiram realizar alguma ação, 31\% utilizavam instrumentos de registro que mais se aproximam de um roteiro ou checklist de inspeção de ambientes de trabalho.

Embora a intervenção sobre os fatores determinantes e condicionantes dos problemas de saúde relacionados aos processos e ambientes de trabalho conste nos instrumentos legais, Pinheiro (1996) relaciona dificuldades inerentes à implantação de um 
sistema de vigilância que está no âmago do conflito capital-trabalho e é realizado por equipes com dificuldade de compreender esta dimensão das ações.

Atualmente, a Rede Nacional de Atenção Integral à Saúde do Trabalhador (Renast), atualizada pela Portaria MS no 2.728/09 (BRASIL, 2009), tem respondido às dificuldades, em especial no que tange aos recursos e à capacitação. Por outro lado, uma nova limitação se apresenta justamente pelo modelo Renast que, segundo Gomez e Lacaz (2005), adotou o modelo de serviços específicos de nível secundário, em apoio à rede SUS, substituindo o modelo anterior que assumia a compreensão da categoria trabalho e articulava a assistência com a vigilância a partir da perspectiva do trabalho como determinante de formas específicas de morbimortalidade. Esta articulação se dava particularmente com a inserção dos serviços na esfera de gestão no nível central. O modelo atual, com a priorização da assistência, acaba por apresentar um impacto pequeno na intervenção sobre os ambientes e os processos de trabalho nocivos à saúde (GOMEZ; LACAZ, 2005). Esta situação ainda não se mostrou de melhor operacionalidade com a inserção da Saúde do Trabalhador na Secretaria de Vigilância em Saúde, no âmbito do Ministério da Saúde, e copiada pelas estruturas adjacentes de Estados e Municípios.

A inserção da Renast no SUS ainda não conta com muita análise. Uma revisão de Leão e Vasconcellos (2011) resume que os estudos disponíveis verificaram concentração na assistência (não raro em consultas de medicina do trabalho), inexistência de informação e falta de canais de comunicação, baixa articulação intrassetorial e baixa comunicação intra SUS. Concluem os autores que, a despeito da designação Centro de Referência em Saúde do Trabalhador, não houve a homogeneização da inserção dos Cerest nas estruturas do SUS.

Algumas dessas dificuldades podem ser explicadas pela formação original das equipes dos Cerest, vinculados à clínica ou às áreas ditas "do trabalho" que repetem o paradigma de atuação da medicina do trabalho e se refletiu no manual de gestão da Renast, de 2006 (BRASIL, 2006).

A organização paulatina da Renast parte da publicação de protocolos, uma série de documentos que oferecem recomendações e parâmetros para diagnóstico, tratamento e prevenção de 12 agravos. Vale destacar a ausência, ainda persistente, de publicações sistematizadoras de ações de vigilância em ambientes e processo de trabalho.

Outro problema diz respeito à delegação da execução das ações de Vigilância em Saúde do Trabalhador para a instância municipal sem a responsabilização solidária da instância estadual do SUS. A estrutura regionalizada da Renast não auxilia nesta etapa, na medida em que não prevê uma função dos centros de referência regionais e estadual no tocante à vigilância. Lacaz $(2000$, p. 9) destaca a atribuição do nível estadual:

[...] normatização das ações, assessoria, formação e apoio técnicos à instância municipal [...], tendo como meta o desenvolvimento de uma metodologia de intervenção nos ambientes e locais de trabalho que adote um rol de diretrizes operacionais [...] deve envolver uma maior capacidade auditora, na perspectiva de garantir a qualidade das ações e serviços executados pelo nível municipal.

Via de regra, a ausência dessas responsabilidades dilui a articulação política potencial e pode reduzir a esfera estadual à mera instância intermediária de repasse de recursos, de rotinas e organização de atividades.

Leão (2011) destaca 3 impasses relativos às práticas de vigilância em saúde do trabalhador no Brasil: a baixa produção teórica em torno das relações entre saúde-trabalho-ambiente; a dispersão e a falta de entrosamento das ações nas vigilâncias epidemiológica, sanitária e ambiental; e a ênfase demasiada na assistência em detrimento das ações de vigilância pelos serviços de saúde, em particular nos Centros de Referência em Saúde do Trabalhador.

Ainda persistem dificuldades ligadas à ausência do compromisso com a Política Interministerial de Segurança e Saúde do Trabalhador assinada em 2005, a Política Nacional de Saúde do Trabalhador e da Trabalhadora (BRASIL, 2012) e, conforme assinalam Gomez e Lacaz (2005), o enfraquecimento dos movimentos sociais e sindicais que dificultam pressões necessárias para a área. Esses entraves estão profundamente vinculados à tendência neoliberal do Estado Mínimo que o governo vem adotando no que tange à política (LACAZ, 2000) e ao caráter do SUS não sistêmico em um Estado omisso em relação ao papel do trabalho na determinação de situações graves passíveis de controle sanitário (VASCONCELLOS, 2007).

Assim, também configura uma necessidade para a área que o SUS possua caráter sistêmico e articulador com outros setores, pactuando não apenas doenças, mas condições apropriadas de vida e trabalho a partir da participação social em um Estado presente e forte, mediador de conflitos a partir da lógica da equidade (proteção aos mais desassistidos) e não da "neutralidade".

Para a Saúde do Trabalhador, a participação dos trabalhadores é premissa básica, todavia, os sindicatos passam por diversas dificuldades. Lacaz (2000) analisa que o contexto de crise de desemprego aberto diminuiu o número de associados e que a reestruturação produtiva, acompanhada da desregulamentação de direitos trabalhistas e previdenciários conquistados ao longo de anos de luta, levou os 
sindicatos a terceirizar assessorias jurídicas e de medicina e segurança do trabalho, desmontou valiosas experiências historicamente acumuladas, como o Departamento Intersindical de Estudos e Pesquisas de Saúde e dos Ambientes de Trabalho (Diesat), e passou a avançar pouco na proposição de cláusulas em saúde e trabalho a ponto de tornarem-se bastante repetitivas e de efetividade muito discutível.

De certa forma, estas posições são um reflexo da mudança de estratégia do movimento sindical que ressurgira no final dos anos 1970, o qual passou da posição de confrontação com o capital para a postura de certa conciliação ou "cooperação conflitiva" (RODRIGUES, 1995) e culmina com o governo Lula a partir de 2003, em que lideranças sindicais com sensibilidade e demandas pela saúde foram compor quadros em instâncias de gestão e não formaram sucessores.

Em 2011, a população economicamente ativa ocupada era estimada em 93.493.000. Destes, 58,9\% (aproximadamente 55 milhões) contribuíam para a Previdência Social e 16,5\% (aproximadamente 15 milhões) eram sindicalizados (INSTITUTO BRASILEIRO DE GEOGRAFIA E ESTATÍSTICA, 2012). Ainda restam aproximadamente 78 milhões não sindicalizados que podem estar inseridos no mercado informal, desocupados, sob a estratégia liberal de "empreendedor"(autônomo) e todas as demais categorias de exercício do trabalho e que atualmente não formulam ou não possuem organização e espaço para se fazerem ouvir nas suas demandas por saúde. Estas, ainda mais que as outras, são objeto da Saúde do Trabalhador e do SUS. No entanto, ao contrário dessa percepção, o planejamento do número e da localização dos Cerests segue o dimensionamento estadual da população economicamente ativa (BRASIL, 2005b).

O tripé da plataforma política neoliberal, composto pelo aprofundamento da abertura da economia nacional, pela privatização de empresas e serviços públicos e pela desregulamentação das relações de trabalho, obteve aceitação junto à grande parte da população e o neoliberalismo no Brasil ganhou corpo, ideias em importantes setores populares (BOITO JUNIOR, 1996) e pouco ou nenhuma resistência de grupos sociais organizados.

Melo (2007) clama pela urgência do reconhecimento da transição da "fábrica cinzenta" à "claridade dos escritórios" para enfatizar a necessidade de atualização da abordagem do campo de Saúde do Trabalhador. Trata-se de reconhecer a complexidade que reestrutura a organização da produção contemporaneamente e que reconstitui o trabalhador coletivo em uma reconfiguração da divisão do trabalho no âmbito dos processos sociotécnicos particulares de trabalho e, de forma articulada com a reestruturação da produção, no nível mundial. A expressão desta dimensão é o avanço das atividades do setor terciário da economia, mas com relações híbridas entre indústria e serviços (MELO, 2007).

Ao se considerar as perspectivas de superação dos entraves, que têm como pano de fundo a globalização e a reestruturação produtiva, a flexibilização das relações de trabalho e o discurso da competitividade e da qualidade total, associados à proposta de Estado Mínimo, de caráter neoliberal, na qual ao mercado é dado o papel de maior regulador das relações econômicas e sociais, pode-se depreender que a solução dos problemas é tarefa das mais complexas (LACAZ, 2000), ainda não iniciada.

Pode-se concluir que a grande missão da Vigilância em Saúde do Trabalhador, inserir a problemática do trabalho no cotidiano das ações da saúde pública, ainda está embrionária.

\section{A saúde do trabalhador frente às exigên- cias do mundo do trabalho}

As novas posições assumidas pela relação entre os seres humanos, o sistema produtivo e o meio ambiente apontam diversos desafios para a área, dentre os quais discutiremos apenas dois, a nosso ver os que impactam a instrumentalização da área para o enfrentamento de suas próprias limitações, o modelo centrado no agravo e na vigilância do período industrial.

\section{Superação do modelo centrado no agravo}

Com todas as limitações da prática de Visat, já discutidas e em um contexto em que a vigilância epidemiológica de agravos apenas começa a estabelecer relação com as ações de vigilância em ambientes e processo de trabalho, a necessidade histórica é de um avanço ainda maior.

Do ponto de vista das finalidades ou dos propósitos da atenção à saúde, superar o modelo centrado na atenção à "demanda espontânea” - ou seja, no atendimento a doentes ou casos notificados - para incluir e priorizar ações de antecipação de riscos e agravos e de promoção da saúde implica tomar como objeto os determinantes dos problemas de saúde. Assim, a atenção se organizaria de modo a incluir não apenas ações e serviços que incidem sobre os "efeitos" (doença, incapacidade e morte), mas, sobretudo, ações e serviços que incidam sobre as "causas" (condições de vida, trabalho e lazer), ou seja, o modo de vida das pessoas e dos diversos grupos sociais (TEIXEIRA, 2002). Sairia, portanto, do modelo medicalizante (VILAÇA, 1996) para abordar cenários capazes de desencadear problemas socioambientais decorrentes do cotidiano do trabalho, constituindo, assim, uma vigilância de cenários e não de agravos. 
Deslocar o eixo de recuperação da saúde através da intervenção nos ambientes de trabalho, exclusivamente, para promover a saúde dos grupos populacionais a partir das demandas sociais que se apresentam, das necessidades articuladas em cenários de complexidade progressiva exige a:

[...] utilização de saberes e tecnologias consentâneas com a ampliação e diversificação do leque de ações e serviços, o que, por sua vez, se reflete na necessidade de mudança no perfil dos sujeitos do processo de trabalho, tanto no plano individual, de cada profissional e trabalhador de saúde, quanto, principalmente, no perfil do "sujeito coletivo", entendido como a população organizada em torno da promoção da saúde e da melhoria da qualidade de vida, em um processo de "apoderamento". (TEIXEIRA, 2002, p. 157)

O deslocamento deste eixo na abordagem da saúde delimita uma nova vigilância antecipatória de cenários.

As recomendações conhecidas de "constituição de serviços de saúde que supere a ineficácia e ineficiência nas ações de promoção, prevenção, manutenção e recuperação da saúde" contrastam necessariamente com o modelo da política neoliberal do Estado Mínimo (LACAZ, 2000).

Um desafio imediato e já bastante discutido é a incorporação da temática ambiental no campo da vigilância em saúde do trabalhador sem a polarizar com questões e demandas específicas dos movimentos de trabalhadores. Trata-se, portanto, de discutir e enfrentar ambos os problemas de forma articulada com a luta pela democracia, a justiça social e a sustentabilidade. Para isso é necessário que a concepção de sustentabilidade inclua a existência e a qualidade do trabalho, além de novos indicadores para a saúde dos trabalhadores como um de seus pilares fundamentais.

A configuração de um modelo múltiplo de vigilância (Ambiental e de Saúde do Trabalhador) foi discutida em Machado et al. (2011), que resumem um projeto a partir de três eixos: um interno ao serviço de vigilância de elaboração metodológica e desenvolvimento de recursos humanos; o segundo eixo de legitimação interna ao SUS se integrando transversalmente ao modelo de atenção integral, de formação de redes técnicas de compartilhamento de informações e de complementação das ações; e o terceiro eixo intersetorial de integração da ação de intervenção nos determinantes sociais do processo saúde-doença.

As consequências de processos produtivos e tecnologias que ignoram ou desprezam as necessidades de seres humanos e do meio ambiente não são enfrentadas somente por especialistas e cientistas, mas pela atuação organizada dos trabalhadores e dos cidadãos em geral na defesa da vida e da democracia (PORTO,
2005). A ampliação do debate para discussões dos impactos à saúde advindos dos grandes empreendimentos e a interferência nas definições das políticas energética, industrial e agrária são exemplos de temas articuladores da saúde como valor no modelo de reprodução social sustentável (MACHADO et al., 2011).

Embora o SUS ainda não disponha de procedimentos bem estabelecidos, a possibilidade legal da relação entre a Visat e a área de Vigilância Ambiental está prevista na Instrução Normativa MS no 1, de 07/03/2005, que se refere às competências na área de vigilância em saúde ambiental (BRASIL, 2005a) e prevê o ambiente de trabalho como fator de risco para a saúde ambiental:

medidas de promoção da saúde ambiental, prevenção e controle dos fatores de riscos relacionados às doenças e outros agravos à saúde, em especial [...] VIII. ambiente de trabalho.

O Ministério da Saúde ainda delimita, nessa Instrução Normativa, as substâncias que serão seus objetos: a "exposição a agrotóxicos, amianto, mercúrio, benzeno e chumbo". Nessa orientação legal, expõe a contradição de chamar para si a responsabilidade de enfrentar apenas alguns contaminantes, ainda não operacionaliza ações conjuntas nem a superação da abordagem focada em agravos e intervenção em fatores e risco.

\section{Modelo pós-fordismo}

A Visat possui profundas relações com o período histórico em que se deu seu desenvolvimento, o modelo fordista de organização da produção. Os novos modelos de organização da produção, do tempo e do espaço, sob a égide da globalização e da flexibilização das relações de trabalho, tendem a ser enfrentados pela Saúde do Trabalhador na mesma lógica controladora da "prevenção" dos novos efeitos identificados, tais como a doença mental, câncer, assédio, trabalho infantil etc. Ou seja, atribui-se aos instrumentos tradicionais, tais como análise de ambiente de trabalho, nexo causal, tempo de exposição e avaliação de risco, a crença de que é possível reverter o pós-fordismo e promover saúde.

O modelo subjacente a estas práticas, baseado na Teoria de Regulação e no papel mediador (e neutro) do Estado, é bem discutido em Braga (2003). Ele assinala a crença de que o pós-fordismo pode trazer o crescimento econômico com equidade ou o "capitalismo mais humano". Critica este modelo e alerta para o perigo das novas formas que a Teoria da Regulação assume e são reinventadas pelos espaços acadêmicos, em particular a busca europeia de pactos sociais em uma perspectiva do "novo reformismo" como alternativa ao neoliberalismo norte-americano. 
Assim, aperfeiçoar esta vigilância serve apenas para retornar à busca dos agravos nos moldes do trabalho industrial, em um processo histórico totalmente distinto sob uma verdadeira nostalgia do fordismo.

Em uma direção distinta das teses que defendiam a ideia do esgotamento ou mesmo do fim do trabalho, Antunes e Alves (2004) analisam as mutações no mundo do trabalho e apontam as seguintes tendências:

1) Com a retração do binômio taylorismo/fordismo, vem ocorrendo uma redução do proletariado industrial, fabril, tradicional, manual, estável e especializado, herdeiro da era da indústria verticalizada de tipo taylorista e fordista. 2) Aumento do novo proletariado fabril e de serviços, em escala mundial, presente nas diversas modalidades de trabalho precarizado. São os terceirizados, subcontratados, part-time, entre tantas outras formas assemelhadas, que se expandem em escala global. 3) Aumento significativo do trabalho feminino num movimento inverso da temática salarial. 4) Significativa expansão dos assalariados médios no "setor de serviços". 5) Crescente exclusão dos jovens e dos idosos. 6) Expansão do trabalho no chamado "Terceiro Setor" e do trabalho produtivo em domicílio, que mescla-se com o trabalho reprodutivo doméstico, aumentando as formas de exploração do contingente feminino e 7) No contexto do capitalismo mundializado, dado pela transnacionalização do capital e de seu sistema produtivo, a configuração do mundo do trabalho é cada vez mais transnacional. (ANTUNES; ALVES, 2004, p. 336)

Os autores concluem com uma possível explicação para o desinteresse das lutas por saúde e a dinâmica atual de alienação social e política que tanto prejudica a organização do controle social no SUS:

\footnotetext{
Neste contexto de capital mundializado caracterizado pelo desemprego estrutural, pela redução e a precarização das condições de trabalho, evidencia-se a existência de uma materialidade adversa aos trabalhadores, um solo social que constrange ainda mais o afloramento de uma subjetividade autêntica, ou seja, de uma subjetividade para-si[...] E repercute na vida e na esfera da reprodução societal, na qual o consumo de mercadorias, materiais ou imateriais, também está em enorme medida estruturado pelo capital. Desde os serviços públicos cada vez mais privatizados, até o turismo, no qual o "tempo livre" é instigado a ser gasto no consumo dos shoppings, são enormes as evidências dos obstáculos ao desenvolvimento de uma subjetividade autêntica. Nessas condições, a subjetividade da classe é transformada em um objeto, em um "sujeito-objeto", que funciona para a auto-afirmação e a reprodução de uma força estranhada. O indivíduo chega a auto-alienar suas possibilidades mais próprias, vendendo, por exemplo, sua força de trabalho sob condições que lhe são impostas, ou, em outro plano, sacrifica-se ao consumo de prestígio, "imposto pela lei de mercado”. (ANTUNES; ALVES, 2004, p. 349)
}

O paradoxo deste movimento econômico fica muito claro se estabelecemos uma analogia com a situação do trabalhador rural, em especial o plantador de cana-de-açúcar. Quando o Brasil ampliava sua produção de açúcar, os riscos estavam associados aos acidentes com corte, amputação e picada de animal peçonhento, especialmente cobras. Com o Proálcool, na década de 1980, os riscos estudados se ampliam para a exposição solar, a pneumoconiose (bagaçose), a dermatose do contato com as folhas de cana e, em uma dimensão mais social, o trabalho infantil. Atualmente, o modelo energético que o Brasil apresenta ao mundo acumula as mazelas anteriores e ainda gera morte de trabalhadores por exaustão $\left(\right.$ Karoshi $\left.^{2}\right)$ em um paradoxo evidente do modelo econômico e a omissão de sua repercussão sobre a força de trabalho, contradição que faz calar nosso instrumental técnico e fala por si só.

Se o campo da Saúde do Trabalhador reconhece que as relações trabalho-saúde dizem respeito a quaisquer trabalhadores, independentemente da forma como se dá a inserção no trabalho, a questão central das políticas e da recomposição do trabalhador reside tanto na investigação, quanto na intervenção (MELO, 2007), que se expressam nas ações da Visat.

Esta Visat, que investiga e atua em uma perspectiva da apreensão dos determinantes da Saúde do Trabalhador, demanda um novo "sistema" de registro da realidade. Ou seja, é insuficiente o registro de agravos isolados de sua cadeia causal e necessário valorizar os problemas vividos. No entanto, apreender e expressar problemas vividos e priorizados requer a construção de "cenários epidemiológicos" com dimensão que vai além de coeficientes; são evidências traduzidas em indicadores complexos e qualitativos.

Instituir instrumentos que expressem estes determinantes implicará em uma verdadeira revolução cultural e uma real alteração dos padrões de gestão contemporânea, balizando com dados concretos o planejamento, os contratos de gestão e o acompanhamento permanente de sistemas locais e de serviços de saúde (CAMPOS, 2007) e não é menos que isto que estamos buscando.

Se pensarmos nas relações saúde-trabalho-desenvolvimento como eixo, incluídas as variáveis produção, meio ambiente, sustentabilidade e a felicidade humana, as políticas de saúde devem incorporar às suas macrodiretrizes as questões da produção e do desenvolvimento socioambiental do mesmo modo que as de trabalho/produção devam incorporar

\footnotetext{
${ }^{2}$ Karoshi: Termo utilizado no Japão para definir "morte por excesso de trabalho", no qual Karo significa excesso de trabalho e Shi, morte. É descrito na literatura sociomédica como um quadro clínico extremo (ligado ao estresse ocupacional) com morte súbita por acidente vascular coronariano ou vascular cerebral.
} 
questões sutis de saúde e meio ambiente e assim por diante. A possibilidade de que isso ocorra depende de níveis macro de articulação das estruturas definidoras nas instâncias de decisão, fato não experimentado ainda no SUS (VASCONCELLOS, 2007).

\section{O caminho, o cenário e os passos}

As dificuldades e os desafios são os dois horizontes apresentados. Vislumbrá-los assusta e dimensiona o quanto ainda há de vir. Enfrentá-los é uma questão de coragem.

Sem ousar apontar regras, mas recolhendo o tanto que já vem sendo pensado e produzido, passo a discutir uma proposta de caminho e a elencar passos possíveis em direção a um modelo desejado.

Se for notório que, para a vigilância, o tipo de recorte da realidade (indicador) contém em si mesmo as evidências escolhidas para serem enfrentadas (causas) e aponta os horizontes das ações, cabe tentar alcançar a instância mais avançada, a determinação socioambiental dos problemas. Em uma perspectiva de superar o modelo vigente, centrado no efeito final, e partir para instrumentos evidenciadores dos níveis de determinação, faz-se mister pensar, necessariamente, em novos paradigmas nos campos teóricos e operacionais.

A atuação prática da Visat em níveis de complexidade, segundo a capacidade técnica, a organização do SUS e a responsabilidade sanitária, já vem sendo discutido por Ribeiro (2001, 2013), Campos (2007) e Vasconcellos (2007).

Refletindo sobre a dificuldade de adesão do movimento social e das estruturas sociais ao objeto da área de Saúde do Trabalhador, qual seja, o papel determinante que o trabalho exerce na vida da população e no ambiente, associada às desigualdades sociais e territoriais como fator fundamental para esta questão, cabe repensar se, em vez de trabalhar com nossos recortes de efeito para sensibilizar a sociedade, não será mais operacional identificar, a partir das demandas da sociedade, a função do trabalho nas necessidades reconhecidas por ela.

Em uma perspectiva de planejamento, significa reconstruir indicadores de produção-saúde-ambiente a partir das demandas configuradas pela população. Breilh (2003) indica como instrumento a construção de matriz de processo crítico e de intervenção no monitoramento intercultural.

O lócus desencadeador deste movimento são as práticas nos conselhos de saúde com a intenção clara de sensibilização da consciência sanitária tanto da população, como dos próprios servidores públicos dos mais diversos setores, propiciando a construção de alianças capazes de atuar no sentido de elevar a cidadania e não apenas na reparação da saúde, através da incorporação de projetos populares e interferência sobre as decisões relativas às políticas públicas. A atuação em rede tem sido proposta como uma estratégia por Machado e Porto (2003).

Em uma perspectiva de etapas, pode-se sucintamente sugerir três momentos: a pactuação dos cenários; a adoção de novos indicadores; e a avaliação sistemática.

A primeira e mais importante etapa consiste em identificar e planejar ações tomando por base indicadores de médio, longo e curto prazos. Indicadores técnicos conjugados podem ser derivados, por exemplo, da epidemiologia (da exposição), da antropologia (situação indígena), da sociologia (conflito dos sem terra, assédio moral, gênero, trabalho infantil etc.), da vigilância ambiental (radiação) e de outros campos de conhecimento, associando-se aos problemas trazidos pelos grupos sociais, como sindicatos, associação de moradores, trabalhadores informais, ONG ambientais etc. e iniciando-se a configuração do cenário que será objeto da vigilância.

Nesta etapa de eleição e pactuação dos projetos para alcançar cenários desejáveis, o objetivo é priorizar indicadores compartilhados com os atores sociais que sofrem os impactos negativos, apontar e eleger caminhos conjuntos, consensuados pela disposição de trabalho das organizações presentes. Pactuação de projetos e cenários consiste na eleição do horizonte comum aos atores sensíveis ao tema da Saúde do Trabalhador em um determinado momento e período histórico. Este momento, atualmente, são as conferências de Saúde do Trabalhador que precisam romper com a lógica burocratizante de checklist e partir para a construção de novas estratégias locais e nacionais que atendam às diferentes percepções de saúde, aglutine e garanta o protagonismo de variados atores sociais. Outros fóruns podem ser tanto ou mais profícuos para a área, como a Conferência das Nações Unidas sobre o Desenvolvimento Sustentável (Rio+20), o Fórum Social Mundial, a Conferência de Conflitos Socioambientais e Direitos Humanos, apenas para lembrar os de amplitude internacional.

Um exemplo de atividade antecipatória da Visat, a ser aplicada nesta etapa, pode ser um conjunto de ações em áreas de grandes empreendimentos como instalação de refinarias ou barragens. Outros exemplos podem ser a estratégia de mapeamento nacional do consumo de amianto ou de agrotóxicos. A factibilidade desta estratégia já possui exemplo no "Mapa da Exposição à Sílica no Brasil" (RIBEIRO, 2010). O modelo Justiça Ambiental (LOUREIRO; LAYRAR GUES, 2013; PORTO; FINAMORE, 2012), por sua vez, tornou visível os conflitos brasileiros com o "Mapa da Injustiça Ambiental e Saúde no Brasil" (LIS/ICICT/ FIOCRUZ, 2013). 
A segunda etapa de implementação de novos indicadores, ou a etapa da arte, mais do que técnica, constitui-se em uma ousadia acadêmica e política de gerar categorias de análise construídas a partir de um ponto de vista crítico, com a participação dos atores sociais e de suas percepções, sob enfoque inter/transdisciplinar com a flexibilidade para trabalhar com a incerteza, uma vez que as soluções para os problemas demandados não estão definidas a priori. Algumas propostas metodológicas são discutas por Augusto, Camara e Carneiro (2003). A Visat, neste momento, incorpora e supera os indicadores técnicos de desfecho e se volta para as evidências de antecipação dos "riscos" partindo de cenários que se desejam construir.

A expectativa é que este processo envolva com muito mais afinco o movimento social historicamente colocado como objeto e não ator da saúde. Isto porque as metas já não são apenas aquelas identificadas pelos indicadores de agravos, mas podem (e devem) ser preocupações sociais mais amplas, como o reflexo na vida de um município a partir da instalação de polos industriais, de novas formas de agricultura. Trata-se de traduzir em indicadores as evidências percebidas e vividas. Enfim, sempre haverá, nestes problemas, uma forte carga de comprometimento da saúde e caberá ao grupo transformá-los em indicadores de processo e meta final. Espera-se, nesta etapa conflitos, negociação e um intenso movimento dinâmico que não pode ser frustrado pela falta de legislação, técnica ou recursos (pessoal, financeiro e humano). A arte desta etapa está, justamente, na construção dos novos caminhos para responder às expectativas, que muitas vezes vai retornar na valorização de indicadores de morbimortalidade ou de exposição tradicionais e outras vezes em indicadores conjuntos com outras áreas, como o ambiente, a educação, o desenvolvimento social ou o trabalho.

O próprio cenário sociopolítico e a lógica territorial permitirá a eleição de atividades que possam reintegrar o movimento social com a rede instalada em todos os níveis do SUS, ou fora dele, identificando espaços de resposta às demandas de Saúde do Trabalhador e visando à promoção da saúde como objeto fim.

A terceira etapa, a avaliação permanente e pública, é fundamental e necessariamente a mais complexa, quando os insucessos devem ser discutidos na perspectiva de seus determinantes e não na identificação de culpas. Indicadores apropriados para esta etapa devem ser avaliados e repactuados. Por sua vez, os projetos bem-sucedidos devem ganhar voz e ecoar por todo o país para que estimulem solidariamente outros processos na contramão do comportamento individualista e de competição entre regiões e nações. A Vigilância Antecipatória de Cenários consistirá no monitoramento dos projetos eleitos na primeira etapa e na revisão das estratégias e dos indicadores.
Algumas dimensões precisam ser entendidas como básicas para uma política de saúde que contemple a determinação do trabalho sobre a vida e a saúde. A primeira delas é a intolerância para algumas situações, tais como a inserção de crianças no processo de trabalho, a utilização de substâncias ou processo tecnológicos altamente danosos à saúde com alternativas conhecidas e não adotadas pela pressão econômica, como o amianto, o jateamento de areia e diversas substâncias cancerígenas. Outra dimensão importante é a necessidade de reformulação contínua da legislação que ampare e promova a vida em todos os seus aspectos, seja rechaçando todo e qualquer limite de tolerância para determinadas substâncias, seja na proteção à mulher, aos adolescentes e aos mais vulneráveis social e biologicamente.

Por fim, é pressuposto compreender os processos produtivos e as estratégias de trabalho como geradores de pressão e produtores de desigualdades e de iniquidades, reprimindo, em todas as esferas legais e sociais, o ambiente e a organização de trabalho que não promova o crescimento e a potencialização da vida, ainda que para isso seja necessário rever o conhecimento, a legislação ou a estratégia do SUS, pautando-se nos princípios da ética e da dignidade da vida humana.

\section{Respostas para algumas não perguntas:}

Em um plano direto e de curto prazo, pode-se enunciar algumas conjecturas operacionais:

1. Estabelecer como plano de trabalho básico a identificação dos empecilhos e a implementação das informações de Saúde do Trabalhador em todos os instrumentos da Vigilância Epidemiológica e Sanitária.

2. Valorizar a vigilância dos expostos através de um Sistema de Registro Obrigatório de Exposição a Agentes Químicos ou sistema correlato com registro nominal de trabalhadores expostos, pelo menos, aos cancerígenos (amianto, sílica, benzeno, agrotóxicos e radiação solar), a substâncias químicas ou agentes físicos de interesse regional específico.

3. Participar de forma importante e prioritária das formulações de gestão do SUS, alçando interferir nos modelos de organização, como o Pacto Pela Vida e Pela Gestão (BRASIL, 2006), o Contrato Organizativo da Ação Pública da Saúde - Coap (SILVA JUNIOR, 2013), introduzindo a Visat articulada aos temas prioritários já eleitos e às consequências à saúde decorrente do trabalho como prioridade e responsabilidade da gestão em todas as suas instâncias. 
4. Antecipar-se aos problemas a partir da adoção de um planejamento baseado no território, visto como "um espaço em permanente construção, produto de uma dinâmica social onde tensionam sujeitos sociais postos na arena política e que envolve componentes econômicos, políticos, culturais e epidemiológicos que devem ser permanentemente avaliados para uma maior eficácia das ações de saúde" (LACAZ, 2000). Nesta atividade, a articulação com a Universidade é fundamental, seja como centro colaborador, seja articulando os projetos financiados pelo Fundo Nacional de Saúde.

5. Estabelecer uma orientação nacional da área de Saúde do Trabalhador focada em metas comuns. Sem perder de horizonte os determinantes, priorizar metas que já possuem acúmulo técnico e demandem a articulação das vigilâncias, com revisões, pelo menos, anuais. Nesta mesma direção é importante adotar uma estratégia de capacitação permanente nesta nova lógica.

\section{Em médio prazo}

6. Implantar a Vigilância Antecipatória de Cenários a partir da reconstrução dos Planos de Saúde do Trabalhador não burocráticos e mais comprometidos, em cada município, incorporando e ampliando a sua dimensão no Estado e potencializados no Plano Nacional.

7. As especificidades do financiamento da Visat, além de inseridas nas pactuações, podem ser reforçadas na responsabilização do empregador que gera o risco e produz o acidente ou o adoecimento, similar ao princípio "poluidor-pagador" proposto pela área ambiental (AUGUSTO; CAMARA; CARNEIRO, 2003) e já previsto nas ações regressivas da Previdência Social (Lei nº 8212) (BRASIL, 1991) para o mercado formal.

\section{Referências}

ANTUNES, R.; ALVES, G. R. As mutações no mundo do trabalho na era da mundialização do Capital. Educação e Sociedade, Campinas, v. 25, n. 87, p. 335351, maio/ago. 2004.

AUGUSTO, L. G. S.; CAMARA, V. M.; CARNEIRO, F. F. et al. Saúde e ambiente: uma reflexão da Associação Brasileira de Pós-Graduação em Saúde Coletiva Abrasco. Revista Brasileira de Epidemiologia, São Paulo, v. 6, n. 2, p. 87-94, jun. 2003.
8. Assumir que a Política de Saúde do Trabalhador apresenta interfaces com as políticas de desenvolvimento, econômicas, de indústria e comércio, agricultura, ciência e tecnologia, educação e justiça, além de estar diretamente relacionada às políticas do trabalho, previdência social e meio ambiente, comprometendo estas políticas com as metas nacionais de Saúde do Trabalhador. Logo, enfrentar as consequências do processo de trabalho sobre a saúde deve estar introjetada nas atividades destes setores, bem como nas organizações de trabalhadores e nas estruturas organizadas da sociedade.

\section{Em longo prazo}

9. Uma política de Estado que remodele a vigilância em saúde com direções intra e trans-setoriais, na perspectiva de um SUS sistêmico, com a inovação de uma nova inteligência de vigilância, abarcando as áreas afins no planejamento, no orçamento compartilhado de algumas rubricas e no compartilhamento do plano de ações (VASCONCELLOS, 2007).

10. Desenvolver e operacionalizar um sistema de informação capaz de captar os indicadores qualitativos e apontar determinantes sociais.

11. Interpor, no modelo de desenvolvimento socioeconômico, a valorização da sustentação da cultura, das heterogeneidades nacionais e do potencial humano.

Espera-se que algumas ousadias libertem o potencial flectido e que possa ser desvelada a grande missão da Vigilância em Saúde do Trabalhador, que se constitui em inserir a problemática do trabalho no cotidiano das ações da saúde pública e, primordialmente, identificar no Estado a responsabilidade na forma e nas condições como a população produz a riqueza, os recursos e a cultura do país.

BOITO JUNIOR, A. Hegemonia neoliberal e sindicalismo no Brasil. São Paulo: Editora Brasiliense, 1996.

BRAGA, R. A nostalgia do fordismo: modernização e crise na teoria da sociedade salarial. São Paulo: Xamã, 2003.

BRASIL. Lei no 8.080, de 19 de setembro de 1990. Dispõe sobre as condições para a promoção, proteção e recuperação da saúde, a organização e o 
funcionamento dos serviços correspondentes e dá outras providências. Diário Oficial [da] República Federativa do Brasil, Brasília, DF, 19 de setembro de 1990. Disponível em < http://presrepublica.jusbrasil. com.br/legislacao/109386/lei-8080-90 > . Acesso em: 22 nov. 2013.

. Lei Orgânica da Seguridade Social - Lei $\overline{\mathrm{n}^{\circ}}$ 8.212, de 24 de julho de 1991. Dispõe sobre a organização da Seguridade Social, institui Plano de Custeio, e dá outras providências. Diário Oficial [da] República Federativa do Brasil, Brasília, DF, 27 de julho de 1991. Disponível em: < http://presrepublica.jusbrasil. com.br/legislacao/126785/lei-organica-da-seguridadesocial-lei-8212-91>. Acesso em: 22 nov. 2013.

. Ministério da Saúde. Instrução Normativa $\overline{\mathrm{n}^{\circ}} 1$, de 07 de março de 2005. Regulamenta a Portaria $\mathrm{GM} / \mathrm{MS} \mathrm{n}^{\mathrm{0}}$ 1.172/04, no que se refere às competências da União, estados, municípios e Distrito Federal na área de vigilância em saúde ambiental. Diário Oficial [da] República Federativa do Brasil, Brasília, DF, 08 de março de 2005a. Disponível em: < http://portal.saude. gov.br/portal/arquivos/pdf/inst_normativa_01_2005. pdf $>$. Acesso em: 22 nov. 2013.

. Portaria $\mathrm{n}^{\mathrm{o}}$ 104, de 25 de janeiro de 2011. Define as terminologias adotadas em legislação nacional, conforme o disposto no Regulamento Sanitário Internacional 2005 (RSI 2005), a relação de doenças, agravos e eventos em saúde pública de notificação compulsória em todo o território nacional e estabelece fluxo, critérios, responsabilidades e atribuições aos profissionais e serviços de saúde. Diário Oficial [da] República Federativa do Brasil, Brasília, DF, 26 de janeiro de 2011. Disponível em: < http://portal.saude. gov.br/portal/arquivos/pdf/portaria_104_26_2011_dnc. pdf>. Acesso em: 22 nov. 2013.

. Portaria no ${ }^{\circ}$ 399/GM, de 22 de fevereiro de 2006. Divulga o pacto pela saúde 2006 - Consolidação do SUS e aprova as diretrizes operacionais do referido pacto. Diário Oficial [da] República Federativa do Brasil, Brasília, DF, 23 de fevereiro de 2006. Disponível em: <http://bvsms.saude.gov.br/bvs/saudelegis/ gm/2006/prt0399_22_02_2006.html >. Acesso em: 22 nov. 2013.

. Portaria no 1.823 , de 23 de agosto de 2012 . Institui a Política Nacional de Saúde do Trabalhador e da Trabalhadora. Diário Oficial [da] República Federativa do Brasil, Brasília, DF, 24 de agosto de 2012. Disponível em: <http://bvsms.saude.gov.br/ bvs/saudelegis/gm/2012/prt1823_23_08_2012.html >. Acesso em: 22 nov. 2013.

. Portaria $\mathrm{n}^{\mathrm{o}} 2.728$, de 11 de novembro de 2009. Dispõe sobre a Rede Nacional de Atenção Integral à Saúde do Trabalhador (RENAST) e dá outras providências. Diário Oficial [da] República Federativa do Brasil, Brasília, DF, 12 de novembro de 2009. Disponível em: <http://bvsms.saude.gov.br/bvs/saudelegis/gm/2009/ prt2728_11_11_2009.html>. Acesso em: 22 nov. 2013.
. Portaria n⿳0 3.120, de 01 de julho de 1998.

Aprova a instrução normativa de vigilância em saúde do trabalhador no SUS, na forma do anexo a esta Portaria, com a finalidade de definir procedimentos básicos para o desenvolvimento das ações correspondentes. Diário Oficial [da] República Federativa do Brasil, Brasília, DF, 02 de julho de 1998a. Disponível em: <http://www. cerest.rn.gov.br/contentproducao/aplicacao/sesap_cerest/ legislacao/gerados/portaria\%203.120.pdf > . Acesso em: 22 nov. 2013.

Portaria $n^{\circ} 3.908$, de 30 de outubro de 1998. Estabelece procedimentos para orientar e instrumentalizar as ações e serviços de saúde do trabalhador no Sistema Único de Saúde (SUS). Diário Oficial [da] República Federativa do Brasil, Brasília, DF, 10 de novembro de 1998b. Disponível em: < http:// www.saude.rs.gov.br/upload/1337000641_Portaria\%20 MS\%20n\%C2\%BA\%203908\%201998\%20NOST.pdf>. Acesso em: 22 nov. 2013.

. Rede Nacional de Atenção Integral à Saúde do Trabalhador. Manual de Gestão e Gerenciamento. Renast/MS/ Hemeroteca Sindical Brasileira. São Paulo. 2006. Disponível em: <http://portal.saude.gov.br/ portal/arquivos/pdf/ManualRenast07.pdf>. Acesso em: 15 fev. 2012.

BREILH, J. De la vigilancia convencional al monitoreo participativo. Ciência e Saúde Coletiva, Rio de Janeiro, v. 8, n. 4, p. 937-951, 2003.

CASTIEL, L. D.; GUILAM, M. C. R.; FERREIRA, M. S. Correndo o risco: uma introdução aos riscos em saúde. Rio de Janeiro: Fiocruz, 2010.

CAMPOS, G. W. S. Reforma política e sanitária: a sustentabilidade do SUS em questão? Ciência e Saúde Coletiva, Rio de Janeiro, v. 12, n. 2, p. 301-306, 2007.

COSTA, F. P. Protocolo de Vigilância em Saúde do Trabalhador: uma contribuição crítica. 2011. 186 f. Dissertação (Mestrado em Saúde Pública)-Faculdade de Medicina, Universidade Federal de Minas Gerais, Minas Gerais, 2011.

GOMEZ, C. M.; LACAZ, F. A. C. Saúde do trabalhador: novas-velhas questões. Ciência e Saúde Coletiva, Rio de Janeiro, v. 10, n. 4, p. 797-807, 2005.

INSTITUTO BRASILEIRO DE GEOGRAFIA E ESTATÍSTICA. Pesquisa Nacional de Amostra por Domicílios - síntese de indicadores, 2011. Rio de Janeiro: IBGE, 2012. Disponível em: <ftp://ftp.ibge. gov.br/Trabalho_e_Rendimento/Pesquisa_Nacional_ por_Amostra_de_-Domicilios_anual/2011/Sintese_ Indicadores/sintese_pnad2011.pdf. > . Acesso em: 23 nov. 2013.

LACAZ, F. A. C. Saúde do trabalhador: cenários e perspectivas numa conjuntura privatista. Montevideo: UITA, 2000. Disponível em: < http://www6.rel-uita.org/ old/home/ler/informes/saude_do_trabalhador.htm $>$. Acesso em: 23 nov. 2013. 
LACAZ, F. A. C.; MACHADO, J. M. H.; PORTO, M. F. S. Relatório Final do Projeto. Estudo da situação e tendências da Vigilância em Saúde do Trabalhador no Brasil. OPAS/ Abrasco, 2002. Disponível em: <http:// www.opas.org.br/saudedotrabalhador/arquivos/ Sala187.pdf>. Acesso em: 12 fev. 2012.

LEÃO, L. H. C. Nas trilhas das cadeias produtivas: subsídios para uma política integradora de vigilância em saúde. 2011. 192 f. Dissertação (Mestrado em Saúde Pública)-Escola Nacional de Saúde Pública, Fundação Oswaldo Cruz, Rio de Janeiro, 2011.

LEÃO, L. H. C.; VASCONCELLOS, L. C. F. Rede Nacional de Atenção Integral à Saúde do Trabalhador (Renast): reflexões sobre a estrutura de rede. Epidemiologia em Serviços de Saúde, Brasília, v. 20, n. 1, p. 85-100, jan./mar., 2011.

LIS/ICICT/FIOCRUZ. Mapas de conflitos envolvendo injustiça ambiental e saúde no Brasil. Disponível em: <http://www.conflitoambiental.icict.fiocruz.br/index. php>. Acesso em: 25 ago. 2013.

LOUREIRO, C. F. B.; LAYRARGUES, P.

P. Ecologia política, justiça e educação ambiental crítica: perspectivas de aliança contrahegemônica. Trabalho, Educação e Saúde, Rio de Janeiro, v. 11, n. 1, p. 53-71, 2013.

MACHADO, J. M. H. A heterogeneidade da intervenção: alternativas da vigilância em saúde do trabalhador. 1996. 166 f. Tese (Doutorado em Saúde Pública)-Escola Nacional de Saúde Pública, Fundação Oswaldo Cruz, Rio de Janeiro, 1996.

MACHADO, J. M. H. et al. Vigilância em saúde ambiental e do trabalhador: reflexões e perspectivas. Caderno de Saúde Coletiva. Rio de Janeiro, v. 19, n. 4, p. 399-406, 2011.

MACHADO, J. M. H.; PORTO, M. F. S. Promoção da saúde e intersetorialidade: a experiência da vigilância em saúde do trabalhador na construção de redes. Epidemiologia em Serviços de Saúde, v. 12, n. 3, p. 85100, jan./mar. 2003.

MELO, A. I. S. C. Trabalho e saúde: um estudo entre trabalhadores de serviços de tecnologias da informação. 2007. 298 f. Tese (Doutorado em Saúde Pública)-Escola Nacional de Saúde Pública, Fundação Oswaldo Cruz, Rio de Janeiro, 2007.

MINAYO, M. C. Debate on the paper by Naomar Almeida Filho "For a General Theory of Health: Preliminary Epistemological and Anthropological Notes”. Cadernos de Saúde Pública, Rio de Janeiro, v. 17, n. 4, p. 776-778, 2001.

. Portaria $\mathrm{n}^{\mathrm{o}} 2.728$, de 11 de novembro de 2009. Dispõe sobre a Rede Nacional de Atenção Integral à Saúde do Trabalhador (RENAST) e dá outras providências. Diário Oficial [da] República Federativa do Brasil, Brasília, DF, 12 de novembro de 2009. Disponível em: <http://bvsms.saude.gov.br/ bvs/saudelegis/gm/2009/prt2728_11_11_2009.html>. Acesso em: 22 nov. 2013.
PINHEIRO, T. M. M. Vigilância em Saúde do Trabalhador no Sistema Único de Saúde: a vigilância do conflito e o conflito da vigilância. 1996. 189 f. Tese (Doutorado em Saúde Coletiva)-Faculdade de Ciências Médicas, Universidade Estadual de Campinas, Campinas, 1996.

PORTO, M. F. Saúde do trabalhador e o desafio ambiental: contribuições do enfoque ecossocial, da ecologia política e do movimento pela justiça ambiental. Ciência e Saúde Coletiva, Rio de Janeiro, v. 10, n. 4, p. 829-839, 2005.

PORTO, M. F.; FINAMORE, R. Riscos, saúde e justiça ambiental: o protagonismo das populações atingidas na produção de conhecimento. Ciência e Saúde Coletiva, Rio de Janeiro, v. 17, n. 6, p. 14931501, 2012.

RIBEIRO, F. S. N. Mapa da exposição à sílica no Brasil. UERJ/Ministério da Saúde, 2010. Disponível em: <http://bvsms.saude.gov.br/bvs/publicacoes/mapa exposicao_silica_brasil.pdf>. Acesso em: 15 jan. 2012.

. Metodologia progressiva e integrada de vigilância em saúde do trabalhador no SUS. In: CORREAA, M. J. M.; PINHEIRO, T. M. M.; MERLO, A. R. C. Vigilância em saúde do trabalhador no Sistema Único de Saúde: teorias e práticas. Belo Horizonte: Coopmed, 2013. p. 1445-1477.

. Metodologia progressiva e integrada de vigilância em saúde do trabalhador no SUS: uma proposta de trabalho. In: CONGRESSO PAULISTA DE SAÚDE COLETIVA, 7. 2001, Santos. Resumos... Santos: Associação Paulista de Saúde Pública, 2001. p. 34-43. Disponível em: <http://www.apsp.org. br/divulga/congressos/07_Congresso/VIIcongresso/ oficinas/ofsantos.pdf>. Acesso em: 29 fev. 2012.

RODRIGUES, I. J. O sindicalismo brasileiro da confrontação à cooperação conflitiva. São Paulo Perspectiva, São Paulo, v. 9, n. 3, p. 116-126, 1995.

SILVA JUNIOR, J. B. Reflexões sobre o processo de monitoramento na gestão das ações de vigilância em saúde. Ciência e Saúde Coletiva, Rio de Janeiro, v. 18, n. 5, p. 1220-1221, 2013.

TEIXEIRA, C. F. Promoção e vigilância no contexto da regionalização da assistência à saúde. Cadernos de Saúde Pública, Rio de Janeiro, v. 18, p. 153-162, 2002. Suplemento.

VASCONCELLOS, L. C. F. Saúde, trabalho e desenvolvimento sustentável: apontamentos para uma Política de Estado. 2007. 422 f. Tese (Doutorado em Saúde Pública)-Escola Nacional de Saúde Pública, Fundação Oswaldo Cruz, Rio de Janeiro, 2007.

VASCONCELLOS, L. C. F.; RIBEIRO, F. S. N. Investigação epidemiológica e intervenção sanitária em saúde do trabalhador: o planejamento segundo bases operacionais. Cadernos de Saúde Pública, Rio de Janeiro, v. 13, n. 2, p. 269-275, 1997.

VILAÇA, E. Uma agenda para a saúde. São Paulo: Hucitec, 1996. 